\title{
28 Research Soure \\ Cortical Reorganization in Unilateral Deafness Revealed by Auditory Evoked Response
}

\section{Ji-Hye Han}

Hallym University Medical Center

Jihyun Lee

Hallym University Medical Center

Hyo-Jeong Lee ( $\square$ hyojlee@hallym.ac.kr)

Laboratory of Brain \& Cognitive Sciences for Convergence Medicine, Anyang, Republic of Korea

\section{Research Article}

Keywords: Profound unilateral deafness, hemispheric asymmetry, monaural hearing deprivation

Posted Date: January 28th, 2021

DOl: https://doi.org/10.21203/rs.3.rs-153048/v1

License: (1) This work is licensed under a Creative Commons Attribution 4.0 International License.

Read Full License 


\section{Abstract}

Profound unilateral deafness reduces the ability to detect the location of sounds, which is achieved with binaural hearing. Furthermore, the findings from previous studies have shown that unilateral deafness can cause a substantial change in the pattern of cortical activation, thereby leading to central reorganization in the whole brain. In the present study, we compared N1/P2 auditory cortical activities and the pattern of hemispheric asymmetry of normal hearing, unilaterally deaf, and simulated acute unilateral hearing loss groups during passively listening to speech sounds at different locations. The results show that $\mathrm{P} 2$ latencies were prolonged for left-side stimulation with greater angles in the horizontal plane. In the source analysis, a differential lateralization pattern was revealed such that the N1 source activation in the normal hearing subjects was greater in the left hemisphere, while contralateral activity was found in response to the stimulated side for the right-sided deaf and simulated acute hearing loss groups. However, no hemispheric lateralization was found for the left-sided deaf or simulated acute hearing loss groups. In addition, the cortical N1/P2 activities were inversely related to the duration of deafness in the right auditory region. These findings indicate that the cortical reorganization induced by monaural hearing deprivation differs depending on the side and duration of deafness.

\section{Introduction}

In the United States, at least 3-8.3\% of the general population are unilaterally deaf, while $12-27$ per 100,000 people have acquired unilateral hearing loss ${ }^{1}$. Although the unilaterally deaf population is increasing and the age at onset of deafness substantially varies from childhood to old age, understanding the neurophysiological changes caused by unilateral deafness is limited. Perceptual issues that are mainly associated with unilateral hearing loss include sound localization and understanding speech in noisy environments ${ }^{2}$. Both sound localization and speech perception in noise require adequate functioning of binaural processing. For each task, a listener must successfully encode the information of interaural level difference (ILD) and interaural time difference (ITD), and is sensitive to spectral information ${ }^{3-5}$. However, unilateral hearing loss significantly impairs spatial hearing by disrupting binaural hearing. Moreover, monaural hearing deprivation yields a maladaptive change in the brain that may not be recovered if the deprivation occurs in a critical period of brain development ${ }^{6}$. The findings from a previous report based on large datasets suggest that approximately $50 \%$ of children with unilateral hearing loss are faced with auditory, linguistic, and behavioral issues that cannot be accounted for by audiological factors such as duration of hearing loss or etiology ${ }^{7}$. This has led to the hypothesis that cortical/cognitive factors, and perhaps the degree of neural plasticity, auditory memory, and attention, are together accepted as the source of the issues ${ }^{8}$.

The plasticity of central auditory processing induces functional and/or structural changes in the brain to reorganize neural network following auditory deprivation ${ }^{9-13}$. People with unilateral hearing loss develop a distinct pattern of brain reorganization that is related to poor peripheral representation of the spatial features of sound (e.g., ITD, ILD, and interaural phase difference). In normal hearing listeners, sounds are 
predominantly processed in the hemisphere contralateral to the sound location to integrate spatial cues for precise estimation of the sound location when passively listening to sounds from various positions ${ }^{14}$. Nonetheless, in unilaterally deaf people, the common pattern of contralateral dominance for the ear of stimulation decreased, and more bilateral activation for sound processing was observed ${ }^{15}$. Previous studies have suggested that the enhanced ipsilateral activity to the hearing ear can likely be attributed to the bilateral activation rather than a decrease in contralateral response ${ }^{10,16}$. More importantly, it has been suggested that left-sided and right-sided deafness influence the neurological changes in the brain differently. For example, researchers conducting a neuroimaging study found stronger bilateral responses to complex modulated sounds in left-sided deaf individuals and strong ipsilateral activation on the side of the stimulation in right-sided deaf individuals ${ }^{15}$. Increased bilateral activity in left-sided deaf persons has been repeatedly shown ${ }^{16,17}$ and could be related to a greater degree of cortical reorganization encompassing the frontal cortical regions that are frequently recruited to process degraded speech sounds ${ }^{10}$. Similarly, a recent study assessing cross-modal plasticity in long-term unilateral deafness reported that left-sided deaf individuals exhibited increased connectivity between the brain regions involving visual and sensorimotor networks and the auditory cortex, indicating a larger degree of crossmodal plasticity in left-sided deaf individuals compared to right-sided deaf individuals ${ }^{18}$. However, it has not yet been determined whether such plastic changes in the brain occur to achieve recovery from abnormal binaural sensations to some extent or are merely a consequence of hearing loss $s^{9,10}$

Given that scalp-recorded electroencephalography (EEG) represents neural mechanisms relevant to sound processing at different levels of the auditory system, it has been applied to assess the pattern and degree of cortical reorganization induced by monaural auditory deprivation. The general findings are that deafness in one ear results in substantial changes in neural activity and the pattern of the changes is revealed differently in left- and right-sided deafness. However, findings from some EEG studies examining the influence of the side of deafness on the cortical reorganization have been inconsistent. For example, Hanss et al. ${ }^{16}$ found that left-sided deaf individuals exhibited greater neurophysiological changes, including bilateral activation in response to tone bursts and more ipsilateral activity to the side of stimulation for speech sounds. Contrary to this finding, a significant inverse relationship of cortical N1 responses with behavioral speech perception ability and the duration of deafness was observed only in right-sided deaf persons, indicating greater neurophysiological changes due to right-side deafness over the left-side deafness ${ }^{19}$. In children, the alpha and theta activities during speech-in-noise listening reveal leftward asymmetries for normal hearing, while more lateralized activation on the side of the stimulation was found in unilaterally deaf children, irrespective of the deafness side ${ }^{12}$. Meanwhile, a study on applied $\mathrm{N} 1$ source waveform analysis led the authors to conclude that long-term unilateral deafness did not alter hemispheric asymmetry ${ }^{20}$. Taken together, the effect of the side of deafness on the hemispheric asymmetry in unilateral deafness remains unclear.

In this study, we compared cortical activities of long-lasting unilaterally deaf and $\mathrm{NH}$ participants with one ear noise-masked and occluded to simulate acute unilateral hearing loss. For the simulated acute hearing loss control group, monaural occlusion caused temporal hearing deprivation and imbalance 
between the two ears. The experimental model allowed us to predict how unilateral hearing loss causes functional changes in the central nervous system at the initial stage of chronic unilateral deafness. Considering the high prevalence and wide age range of people with unilateral hearing loss, understanding the neural changes induced by acute unilateral hearing loss would provide important insights into the optimal treatment for asymmetrical hearing loss. Evidence of cortical plasticity following acute unilateral hearing loss has been offered by numerous animal studies ${ }^{21-24}$. It has been reported that neurophysiological changes in the central auditory system are initiated soon after the loss of hearing sensation in one ear. Unilaterally deafened animals showed a considerable threshold shift in the hemisphere ipsilateral to the hearing ear with relatively normal activation in the contralateral side ${ }^{24}$. Kral et al. ${ }^{21}$ demonstrated similar cortical reorganization in cats with acute unilateral hearing loss such that ipsilateral activity to the intact ear increased, and that the degree of enhancement of ipsilateral activity decreased as the onset of deafness was delayed. To date, there have been a limited number of studies directly examining the effect of acute unilateral hearing loss on the human brain. The findings from those studies have suggested that acute unilateral hearing loss can alter normally observed contralateral dominance for the side of stimulation ${ }^{25}$. In addition to the change in hemispheric asymmetry, altered functional connectivity involving widespread areas for auditory, visual, attention, and memory have also been exhibited in acute unilateral hearing loss individuals ${ }^{26}$.

In the current study, our aim was to compare the patterns of cortical activation and hemispheric asymmetry among long-term unilateral deafness, acute unilateral hearing loss, and normal hearing controls. Given the relationship between behavioral spatial processing and cortical reorganization in unilateral deaf, we chose auditory stimuli varied in azimuth to evoke brain responses. Previous studies have suggested that a lesser degree of cortical reorganization was associated with better auditory and speech perception, indicating a clinical need for early intervention for individuals with asymmetrical hearing loss ${ }^{27,28}$. We hypothesized that long-term unilateral deafness would reveal significant cortical reorganization induced by monaural deprivation, and the pattern of hemispheric asymmetry would appear differently in the long-term unilaterally deaf and acute unilateral hearing loss groups. Last, we were concerned with how deafness-induced modulation is related to an audiological factor as measured by the duration of deafness. We hypothesized that the N1/P2 cortical activities in response to auditory stimuli are related to the duration of deafness in unilaterally deaf individuals, suggesting that these cortical responses can be used as markers for neurophysiological change with unilateral hearing loss.

\section{Results}

\section{CORTICAL POTENTIALS}

\section{Effects of sound location and unilateral deafness on N1/P2 cortical potentials}

Figure 1 shows the grand mean waveforms for stimuli at $-60^{\circ},-15^{\circ}, 0^{\circ},+15^{\circ}$, and $+60^{\circ}$ azimuth angles for the NH, RAUHL, LAUHL, RUD, and LUD groups. The overall response was characterized by an N1 evocation at around $100 \mathrm{~ms}$ after stimulus onset, followed by a P2 response. Modulation of $\mathrm{N} 1$ as a 
function of sound location was more apparent at $-60^{\circ}$ and $+60^{\circ}$, and less so at $-15^{\circ}$ and $+15^{\circ}$ azimuth angles.

Repeated-measures ANOVA was applied to examine the effect of sound location $\left(-60^{\circ},-15^{\circ}, 0^{\circ},+15^{\circ},+60^{\circ}\right.$ azimuth angles) and the group effect (NH, RAUHL, LAUHL, RUD, and LUD groups) on N1/P2 measures, with which no significant differences for N1/P2 amplitudes were found. However, significant effects of group $[F(4,46)=3.05 ; p<0.001]$ as well as sound location $[F(4,184)=5.37 ; p<0.001]$ were found for latency measurements. Tukey's HSD post hoc test results show that the P2 latencies in the RAUHL and RUD groups were longer than those for the LUD group ( $p=0.008$ for RAUHL and $p=0.036$ for RUD). For sound location, the $\mathrm{P} 2$ latencies at $-60^{\circ}$ and $+60^{\circ}$ were longer than at $-15^{\circ}\left(p=0.006\right.$ for $-60^{\circ}$ and $p=$ 0.013 for $\left.+60^{\circ}\right), 0^{\circ}(p<0.001$ for both $)$, and $+15^{\circ}\left(p=0.009\right.$ for $-60^{\circ}$ and $p=0.017$ for $\left.+60^{\circ}\right)$. No significant differences for the group and sound location were found for N1 latency.

\section{P2 amplitude is related to the duration of deafness in unilateral deaf}

To determine whether N1/P2 cortical activities are altered by unilateral deafness and whether the change is related to audiological factors, we examined the relationship between electrophysiological measurements and the duration of deafness in the unilaterally deaf subjects. Figure 2 shows that the averaged P2 amplitudes (across all azimuth angles) were negatively correlated with the duration of deafness in the unilaterally deaf groups $(r=-0.7, p=0.025)$, indicating that $\mathrm{P} 2$ decreases as the duration of deafness becomes longer.

\section{SWLORETA SOURCE ANALYSIS}

This analysis was conducted to measure cortical activation in the left and right auditory regions under each set of listening conditions. The VST activations were averaged for the left and right auditory areas to compute the $\mathrm{LI}$ (Figure 3). For swLORETA source activation in the $\mathrm{N} 1$ area, a repeated-measures ANOVA (sound location $\mathrm{x}$ hemisphere $\mathrm{x}$ group) showed a significant main effect for sound location $\left[F\left(_{4}\right.\right.$, $\left.\left.{ }_{184}\right)=3.02 ; p=0.019\right]$, with no effects for hemisphere and group (Figure 3a). A Tukey's HSD post hoc analysis indicates that the $\mathrm{N} 1$ source at $0^{\circ}$ was smaller than at $-60^{\circ}(p=0.009),-15^{\circ}(p=0.013),+15^{\circ}(p=$ $0.037)$, and $+60^{\circ}(p=0.001)$. The results of a repeated-measures ANOVA of LI for the N1 source (sound location $x$ group; Figure $3 b)$ show the main effect for sound location $[F(4,184)=2.41 ; p=0.05]$. Tukey's HSD post hoc test results reveal that the N1 source at $0^{\circ}$ had greater leftward activation compared to $-60^{\circ}$ $(p=0.03),-15^{\circ}(p=0.009)$, and $+15^{\circ}(p=0.036)$. In addition, the results of ANOVA of LI indicate differences across the groups $[F(4,46)=2.76 ; p=0.045]$ such that for $+15^{\circ}$ azimuth angle, the N1 source activation in the $\mathrm{NH}$ group was more lateralized to the left whereas the RAUHL $(p=0.029)$ and RUD ( $p=$ $0.016)$ groups had rightward asymmetries. No hemispheric lateralization was found for the LAUHL and LUD groups.

\section{Differences in source space}


Among many possible comparisons of the conditions, we focused on $-60^{\circ} \mathrm{vs} .+60^{\circ}$ for the following reasons: (1) the results for the cortical potentials suggest that neural modulation as a function of sound location was more robust for $-60^{\circ}$ and $+60^{\circ}$ than the other azimuth angles (Fig. 1); (2) the findings in previous reports suggest that $\mathrm{N} 1$ cortical activity is larger for stimuli containing more prominent spatial cues than for less spatially distinguishable stimuli ${ }^{36}$; and (3) given that the $-60^{\circ}$ and $60^{\circ}$ azimuth angles are closer to the hearing and deafened ears of the subjects than the other angles, these conditions could better represent the effect of unilateral deafness on source activation at the cortical level. Figure 4 shows t-test comparisons of $-60^{\circ}$ with $+60^{\circ}$ for the $\mathrm{NH}, \mathrm{RAUHL}$, and RUD groups. For the $\mathrm{NH}$ group, comparing $-60^{\circ}$ and $+60^{\circ}$ revealed significant clusters $(p=0.001)$ indicating a greater left temporal area (Figure 4 top). For the RAUHL group, significant clusters $(p=0.021)$ in the right anterior temporal and right frontal regions indicate that source activity at $+60^{\circ}$ was larger than at $-60^{\circ}$ (Figure 4 middle). In addition, for the RUD group, a significant cluster $(p<0.001)$ in the right frontal lobe indicates greater activation at $-60^{\circ}$ compared to at $+60^{\circ}$ (Figure 4 bottom). No significant differences were found for the LAUHL and LUD groups.

\section{$\mathrm{N} 1$ source activation is related to the duration of deafness in unilateral deaf}

$\mathrm{N} 1$ source activation values were averaged across all azimuth angles to test them for correlation with the duration of deafness in the unilaterally deaf participants. Figure 5 shows a significant correlation between averaged $\mathrm{N} 1$ source activation and the duration of deafness involving the auditory regions. Figure 5a suggests that lower N1 source activation was associated with a longer duration of deafness. In the brain source space, a negative correlation $(r=-0.65, p=0.013)$ was found bilaterally (but more lateralized to the right hemisphere) in the temporal lobe (Figure $5 b$ ). Figure $5 c$ shows that significant clusters survived after multiple comparison corrections included the right auditory cortex and right inferior temporal lobe.

\section{Discussion}

The aim of this study was to characterize neural changes induced by monaural hearing deprivation during passively listening to consonant-vowel syllables from different locations and to relate these changes to audiological factors in unilaterally deafened people. The neural activities in chronic unilaterally deaf individuals were compared with those in people with acute unilateral hearing loss to assess differences in neural changes between acute and chronic auditory deficits. The results for source analysis suggest that the $\mathrm{N} 1$ source activity in the $\mathrm{NH}$ group was lateralized to the left hemisphere, while no hemispheric asymmetry was found in the left-sided deafness and acute hearing loss groups.

Meanwhile, greater contralateral activation to the side of stimulation was found in the right-sided groups. In addition, both sensor-level P2 and source-level N1 activities were associated with the duration of deafness in unilaterally deaf subjects.

In this study, leftward asymmetry was revealed in NH participants whereas the LUD/LAUHL and RUD/RAUHL groups showed no asymmetry and right-sided lateralization, respectively. Contrary to our 
findings, right-sided dominance for sound localization in normal hearing individuals has been reported in a number of studies since auditory spatial information such as interaural time and intensity cues are mainly processed in the right hemisphere ${ }^{37-39}$. The discordance in the hemispheric asymmetry between our study and the literature could have been raised by the listening paradigm evoking neural responses. Unlike most previous studies in which spectrally varied artificial sounds such as tones, clicks, and noise bursts were applied ${ }^{37,38}$, we used natural speech syllables with a rapid temporal change. It is well recognized that temporal and spectral information sources are preferentially processed in the left and right hemispheres, respectively $30,40,41$. Thus, the greater left hemispheric activation in the $\mathrm{NH}$ participants shown in this study could be related to central auditory processing for temporal information. Another possible explanation for the left hemispheric asymmetry is based on the theoretical assumption that passive listening to sounds is relevant to the implicit learning of acoustic information, which enhances the efficiency of sensory processing ${ }^{42}$. In a lesion study ${ }^{43}$, the evidence suggests that implicit spatial cues containing spatial release from masking were not processed in persons with left hemispheric damage, and explicit sound localization performance is related to the right parietal and the opercular cortex, indicating distinct neural networks for implicit and explicit spatial processing.

In this study, N1 source activation in the RUD and RAUHL groups was greater in the right hemisphere. More specifically, in the RUD group, auditory stimulation of the intact ear elicited greater source activity in the right fronto-parietal cortex whereas larger right hemisphere activation in response to stimuli near the occluded ear was found in the RAUHL group when comparing $-60^{\circ}$ versus $+60^{\circ}$ (see Fig. 4). It is unclear why the RUD and RAUHL groups had distinct neural representations of the $\mathrm{N} 1$ source activity according to the side of stimulation. Nonetheless, we speculate that acute unilateral hearing loss motivated focusing on the stimulus that was difficult to perceive due to the relatively long distance from the hearing ear whereas long-term unilateral deaf subjects were more sensitive to sounds close to their intact ear, which enhanced sensory processing. Under the assumption that the auditory perception of distant stimuli is relevant to sound processing in degraded listening conditions, an increase in N1 response with degraded stimuli could account for the enhancement in N1 source activity to contralateral sounds on the hearing side ${ }^{44,45}$. This finding calls for further study to assess the mechanisms underlying the distinct neural representations of acute hearing loss and chronic deafness.

In contrast to the RUD and RAUHL groups, the LUD and LAUHL groups did not reveal significant hemispheric lateralization in the source analysis. Similar findings from neuroimaging data have been reported in that right-sided deafness enhanced the contralateral response to monaural stimulation whereas left-sided deafness did not promote hemispheric asymmetry ${ }^{10,16,20}$. These results indicate that right- and left-sided deafness could affect cortical reorganization differently because right-sided deafness may be more resistant to plastic changes following hearing deprivation compared to left-sided deafness ${ }^{17,46}$. This notion is possibly supported by the findings of Khosla et al. ${ }^{17}$ who assessed hemispheric asymmetry using dipole source modeling; they found decreased ipsilateral-contralateral amplitude differences only for left-sided deafness, and the reduced interhemispheric activity observed in left-sided deaf individuals is accounted for by increased synaptic plasticity to achieve an excitatory- 
inhibitory balance between the hemispheres ${ }^{24}$. In addition, the results of an earlier study were interpreted as symmetrical hemispheric activity for unilaterally deaf persons is due to increasing ipsilateral activity rather than decreasing contralateral activity to the hearing ear ${ }^{47}$. In the current study, the absence of hemispheric asymmetry in the left-sided deaf subjects could thus be related to enhanced ipsilateral activity to monaural stimulation because of synapse plasticity.

A change in the sound location of the speech sounds evoked N1/P2 responses in this study. Among these, $\mathrm{P} 2$ latencies differed across the subject groups and sound locations such that $\mathrm{P} 2$ responses were prolonged in response to left-side stimulation and azimuth angles of $-60^{\circ}$ and $+60^{\circ}$ compared to rightside stimulation and azimuth angles of $-15^{\circ},+15^{\circ}$, and $0^{\circ}$. The delayed response to the left monaural stimulation could be related to the main hemisphere for processing spatial cues such as the ITD or interaural phase. The spectral information required for accurate sound localization is known to be predominantly processed in the right hemisphere ${ }^{37,38}$. For the RUD and RAUHL group subjects, sounds were presented to the left ear, thereby requiring a longer time to arrive at the right hemisphere through contralateral projection, which could have yielded the P2 prolongation. Similar findings in a previous EEG study were reported in that $\mathrm{N} 1$ latencies measured over the ipsilateral hemisphere in response to the side of stimulation were longer for right-sided deaf participants than left-sided deaf participants ${ }^{19}$. Meanwhile, the longer latency for the $\pm 60^{\circ}$ azimuth angles is likely related to N1/P2 modulation as a function of sound location in that changes in the ITD and the interaural phase or coherence elicited delayed N1/P2 responses because of the longer time needed to process these spatial cues ${ }^{48,49}$. Using the mismatch negativity evoked by infrequent changes in the sound location, Sonnadata et al. ${ }^{49}$ found a longer latency in the positive peak in response to a large angle $\left(90^{\circ}\right)$ compared to a smaller one; they also alluded that this could be partially interpreted by applying the spatial channel theory suggested by Boehnke and Phillips who posited that $0^{\circ}$ and $30^{\circ}$ are processed in the same spatial channel whereas $0^{\circ}$ and $90^{\circ}$ (angles larger than $30^{\circ}$ ) do not share the channel${ }^{50}$. Moreover, according to the theory, spatial location information belonging to different channels is not processed in the lower level of the auditory system but rather in the higher order auditory cortex. Thus, we assume that the prolonged latency for $\pm 60^{\circ}$ azimuth angles could be associated with the precise spatial processing properties of the central auditory system for between-channel discrimination.

Sensor-level P2 responses and source-level N1 activities were significantly associated with the duration of deafness in the area encompassing the auditory cortex. This result suggests that the longer the duration of unilateral deafness, the more substantial the neurological changes at the cortical level, as was reflected by the N1/P2 responses. These findings are in agreement with those from previous studies showing that the changes in cortical activity in unilaterally deaf individuals occur gradually over time after the onset of deafness ${ }^{19,46,51}$. In fact, the relationship between N1/P2 responses and deafness duration is somehow predictable because a large number of auditory-evoked potential studies examining the cortical plasticity have demonstrated that the N1/P2 components are highly responsive to neural changes caused by hearing deprivation and restoration with hearing devices such as cochlear implants ${ }^{52-54}$. For example, in adult unilaterally deaf persons, a decrease in N1 response is associated 
with reduced ability in speech-in-noise perception, and contralateral activity to the side of simulation weakens as the duration of deafness becomes longer ${ }^{12,19}$. Taken together, the findings of studies on unilaterally deafness suggest that people who have experienced a shorter duration of deafness exhibit relatively robust cortical activity due to smaller plastic changes compared to those who have experienced a longer period of hearing loss, indicating a clear need for the early treatment of people with asymmetrical hearing loss.

In summary, we have provided herein additional evidence that unilateral hearing loss can incur a substantial change in central auditory processing and the changes are more prominent for people with longer duration of hearing loss. The neural changes are reflected in N1/P2 cortical responses and the hemispheric lateralization in the brain source space differently for left-sided and right-sided deafness. Our data suggest that early intervention including adequate use of hearing assistive devices could have beneficial outcomes for people with unilateral hearing loss.

\section{Methods}

\section{Participants}

Ten adults who were right-sided unilaterally deaf (RUD; 6 female, mean age: $52.7 \pm 6.2$ years) and 10 who were left-sided unilaterally deaf (LUD; 6 female, mean age: $41.9 \pm 16.8$ years) were recruited through the Department of Otolaryngology in the Hallym University Medical Center. All unilaterally deaf participants were right-handed and had profound hearing loss in one ear (average pure-tone audiometry threshold > $90 \mathrm{~dB} \mathrm{HL}$ ) without hearing devices for more than one year and normal hearing (pure-tone thresholds $<20$ $\mathrm{dB} H \mathrm{HL}$ from 0.25 to $4 \mathrm{kHz}$, and present OAEs) in the other ear. None of the unilaterally deaf groups had used a hearing aid before participating in this study. Thirty age- and gender-matched normal hearing adults were recruited for comparison with the unilaterally deaf groups. The normal controls were subdivided into three groups of 10: a normal hearing group ( $\mathrm{NH}, 7$ female, mean age: $52.2 \pm 6.9$ years), 10 with their left ear noise-masked and occluded (LAUHL: left-side acute unilateral hearing loss, 7 female, mean age: $51.2 \pm 8.3$ years), and 10 with their right ear noise-masked and occluded (RAUHL: right-side acute unilateral hearing loss, 7 female, mean age: $44.1 \pm 16.4$ years). The RAUHL, LAUHL, and NH group participants had normal pure-tone average thresholds in both ears and no neurological and cognitive issues. Informed consent was obtained from all participants prior to testing. All experimental protocols used in this study were approved by the Hallym University Medical Center Institutional Review Board (IRB no. 2019-02-019). All the methods used in this study were performed in accordance to the guidelines and regulations outlined in the Hallym University Medical Center Institutional Review Board (IRB no. 2019-02019). A summary of the demographic data and statistical comparisons among the groups is provided in Table 1.

\section{Table 1.}


Demographic data for the unilateral deafness, acute unilateral hearing loss, and normal hearing groups.

\begin{tabular}{|c|c|c|c|c|c|c|}
\hline & $\begin{array}{l}\text { LUD } \\
(n=10)\end{array}$ & $\begin{array}{l}\text { RUD } \\
(n=10)\end{array}$ & $\begin{array}{l}\text { RAUHL } \\
(\mathrm{n}=10)\end{array}$ & $\begin{array}{l}\text { LAUHL } \\
(\mathrm{n}=10)\end{array}$ & $\begin{array}{l}\mathrm{NH} \\
(n=10)\end{array}$ & Statistics \\
\hline Age (year, mean/SD) & $\begin{array}{l}41.9 \pm \\
16.8\end{array}$ & $\begin{array}{l}52.7 \pm \\
6.2\end{array}$ & $\begin{array}{l}44.1 \pm \\
16.4\end{array}$ & $\begin{array}{l}51.2 \pm \\
8.3\end{array}$ & $\begin{array}{l}52.2 \pm \\
6.9\end{array}$ & $\begin{array}{l}F=1.78, p= \\
0.14\end{array}$ \\
\hline Gender (male/female) & $4 / 6$ & $4 / 6$ & $3 / 7$ & $3 / 7$ & $3 / 7$ & $\begin{array}{l}c^{2}=0.53, p \\
=0.97\end{array}$ \\
\hline $\begin{array}{l}\text { Duration of deafness (year, } \\
\text { mean/SD) }\end{array}$ & $\begin{array}{l}14 \pm \\
16.2\end{array}$ & $\begin{array}{l}19.6 \pm \\
12.1\end{array}$ & & & & $\begin{array}{l}\mathrm{t}=0.86, p= \\
0.39\end{array}$ \\
\hline $\begin{array}{l}\text { Deafness onset (year, } \\
\text { mean/SD) }\end{array}$ & $\begin{array}{l}33.4 \pm \\
22.4\end{array}$ & $\begin{array}{l}24.7 \pm \\
22.4\end{array}$ & & & & $\begin{array}{l}\mathrm{t}=0.27, p= \\
0.78\end{array}$ \\
\hline
\end{tabular}

$L U D$, left-sided unilaterally deaf; $R U D$, right-sided unilaterally deaf; $L A U H L$, left-side acute unilateral hearing loss; RAUHL, right-side acute unilateral hearing loss; $N H$, normal hearing.

\section{Stimuli and procedure}

Figure 6 shows the speech stimuli and sound localization paradigm applied in this study. Natural /ba/-/pa/ speech stimuli were used to evoke cortical responses. The speech stimuli were recorded from utterances by a standard Korean male speaker. The overall duration of each stimulus was $470 \mathrm{~ms}$, and the voice onset times were 30 and $100 \mathrm{~ms}$ for /ba/ and /pa/, respectively (Fig. 6a). The stimuli were presented through a StimTracker (Cedrus Corporation, CA, USA) system that allowed for EEG synchronization with the sound, and they were calibrated using a Brüel and Kjær (2260 Investigator, Nærum, Denmark) sound level meter set for frequency and slow time weighting with a $1 / 2$ inch free-field microphone.

Speech stimuli were presented through five loudspeakers at five different azimuth angles of $-60^{\circ},-15^{\circ}, 0^{\circ}$, $+15^{\circ}$, and $+60^{\circ}$, where ' + ' indicates the right side while '-' indicates the left side (Fig. 6b). Subjects were seated in the center of the speaker array in a sound-attenuated booth. All speakers were located $1.2 \mathrm{~m}$ away from the subject at ear level and sounds were presented at $70 \mathrm{~dB}$ sound pressure level (SPL). Note that for a UHL group, one ear was masked with a masking noise that was delivered through a Bluetooth earphone (QCY 5.0 Earbuds, Beijing, China). The noise masker was speech-shaped noise taken from the speech stimuli used in this study with an overall intensity at a root-mean-squared level of $55 \mathrm{~dB}$ SPL. The inter-stimulus interval from sound offset to onset was fixed at $1.5 \mathrm{~s}$, and stimuli were randomly presented. A total of 1000 trials ( 100 trials each for / ba/ and /pa/ sounds at the five different azimuth angles) were presented across two blocks. During recording, subjects were instructed to ignore sounds while they watched a closed-captioned movie of their choice. Breaks were given upon request. The total recording time was approximately $40 \mathrm{~min}$. 


\section{EEG recording}

Electrophysiological data were collected using a 64-channel actiCHamp Brain Products recording system (Brain Products $\mathrm{GmbH}$, Inc., Munich, Germany). An electrode cap was placed on the scalp with electrodes positioned at equidistant locations ${ }^{29,30}$. The reference channel was positioned at the vertex while the ground electrode was located on the midline $50 \%$ of the distance to the nasion. Continuous data were digitized at $1000 \mathrm{~Hz}$ and stored for offline analysis.

\section{Data processing}

Electrophysiological data were preprocessed using Brain Vision Analyzer 2.0 (Brain Products $\mathrm{GmbH}$, Inc., Munich, Germany). Data were band-pass filtered (1-50 Hz) and down-sampled to $500 \mathrm{~Hz}$. Visual inspection of the data included the removal of artifacts related to subject movement (exceeding $500 \mathrm{mV}$ ). Independent component analysis (ICA $)^{31}$ implemented in Brain Vision Analyzer was applied to remove artifacts related to eye blinking and movement, and cardiac activity.

After ICA artifact reduction, the data were low-pass-filtered at $20 \mathrm{~Hz}$ and segmented from -200 to $1000 \mathrm{~ms}$ with $0 \mathrm{~ms}$ at the onset of the stimulus and re-referenced to the average reference. Averages were obtained for each of the azimuth angles. Subsequent peak detection was performed on fronto-central electrodes for the N1/P2 components. Since we used an electrode cap with equidistant locations, N1/P2 were measured from the averaged activities of three electrodes located at $\mathrm{Cz}$ in the international 10-20 system $^{30,32}$.

\section{Source analysis}

Averaged segments were analyzed in BESA (Brain Electrical Source Analysis) for each electrode location. swLORETA was performed as has been previously described ${ }^{30,33}$. As a first step, swLORETA analysis yielded maximal brain source activations as a function of time. For auditory N1 responses, swLORETA modeling was conducted in a $20 \mathrm{~ms}$ window in which maximal peaks were revealed in the grand mean waveform. Under most conditions, the local maxima include the left and right auditory and frontal regions. Once the source maxima had been identified, the Talairach coordinates of the left and right auditory cortices were used to create grand averaged virtual source time (VST) activation for each condition. Next, two dipoles were inserted at each of the source maxima to obtain activation time courses. In this step, the mean source activation in the $20 \mathrm{~ms}$ window was averaged to obtain VST activation separately for the left and right cortices. The VST was used to compute a lateralization index (LI) for each condition. Positive and negative LI values indicate left- and rightward asymmetries, respectively, and values exceeding \pm 0.2 were considered lateralized ${ }^{34}$.

\section{Statistical analysis}

Repeated-measures ANOVA was performed for the N1/P2 potentials to examine the impact of sound location and subject group on amplitudes and latencies for each component. Post hoc comparisons were 
conducted using Tukey's Honest Significant Difference (HSD) test. To examine relationships between audiological factors and brain responses in unilaterally deaf groups, cortical measures of the N1/P2 were compared with the duration of deafness using Pearson product-moment correlations. Differences in the strength of the brain source space across the listening conditions were tested by applying paired t-tests corrected for multiple comparisons and Monte-Carlo resampling techniques implemented with BESA Statistics $2.0^{35}$. Clusters of voxels with $p$-values of less than 0.05 were considered significant. BESA Statistics was also used to perform correlations between the duration of deafness and source activity for each unilaterally deaf subject. This process yielded a correlation value for each voxel in the brain space related to the source activity and the duration of deafness. Nonparametric cluster permutation tests were conducted to determine the statistical significance of correlations between source activation and the duration of deafness.

\section{Declarations}

Data availability. The datasets generated during the current study are available from the corresponding author on reasonable request.

\section{Acknowledgements}

The authors would like to thank the anonymous reviewers for their very insightful comments. This project was supported by Basic Science Research Program through the National Research Foundation of Korea (NRF) funded by the Ministry of Education (NRF-2020R111A1A01070914, NRF-2020R1A6A3A01099260 \& 2019R1A2B5B01070129), the Center for Women in Science, Engineering and Technology (WISET) Grant funded by the Ministry of Science ICT \& Future Planning of Korea (MSIP) under the Program for Returners into R\&D (WISET-2020-203), and by the Hallym University Research Fund.

\section{Author Contributions}

J-H. H. contributed to the conception and design of the study. J-H. H. and J. L. collected and analyzed the data. All authors (J-H. H., J. L., and H-J. L.) contributed to writing the manuscript.

Competing Interests: The authors declare no competing interests.

\section{References}

1. Baguley, D. M., Bird, J., Humphriss, R. L. \& Prevost, A. T. The evidence base for the application of contralateral bone anchored hearing aids in acquired unilateral sensorineural hearing loss in adults. Clinical Otolaryngology (2006). doi:10.1111/j.1749-4486.2006.01137.x

2. Reeder, R. M., Cadieux, J. \& Firszt, J. B. Quantification of speech-in-noise and sound localisation abilities in children with unilateral hearing loss and comparison to normal hearing peers. in Audiology and Neurotology (2015). doi:10.1159/000380745 
3. Schwartz, A., McDermott, J. H. \& Shinn-Cunningham, B. Spatial cues alone produce inaccurate sound segregation: The effect of interaural time differences. J. Acoust. Soc. Am. (2012). doi:10.1121/1.4718637

4. Shinn-Cunningham, B. G., Durlach, N. I. \& Held, R. M. Adapting to supernormal auditory localization cues. I. Bias and resolution. J. Acoust. Soc. Am. (1998). doi:10.1121/1.423088

5. Darwin, C. J. Contributions of binaural information to the separation of different sound sources. Int. J. Audiol. (2006). doi:10.1080/14992020600782592

6. Harrison, R. V., Gordon, K. A. \& Mount, R. J. Is there a critical period for cochlear implantation in congenitally deaf children? Analyses of hearing and speech perception performance after implantation. Developmental Psychobiology (2005). doi:10.1002/dev.20052

7. Bess, F. H. \& Tharpe, A. M. Unilateral hearing impairment in children. Pediatrics (1984).

8. Kral, A., Kronenberger, W. G., Pisoni, D. B. \& O’Donoghue, G. M. Neurocognitive factors in sensory restoration of early deafness: A connectome model. Lancet Neurol.15, 610-621 (2016).

9. Burton, H., Firszt, J. B., Holden, T., Agato, A. \& Uchanski, R. M. Activation lateralization in human core, belt, and parabelt auditory fields with unilateral deafness compared to normal hearing. Brain Res. (2012). doi:10.1016/j.brainres.2012.02.066

10. Heggdal, P. O. L., Aarstad, H. J., Brännström, J., Vassbotn, F. S. \& Specht, K. An fMRI-study on singlesided deafness: Spectral-temporal properties and side of stimulation modulates hemispheric dominance. Neurolmage Clin. (2019). doi:10.1016/j.nicl.2019.101969

11. Van der Haegen, L. et al. Laterality and unilateral deafness: Patients with congenital right ear deafness do not develop atypical language dominance. Neuropsychologia (2016). doi:10.1016/j.neuropsychologia.2015.10.032

12. Cartocci, G. et al. EEG rhythms lateralization patterns in children with unilateral hearing loss are different from the patterns of normal hearing controls during speech-in-noise listening. Hear. Res. (2019). doi:10.1016/j.heares.2019.04.011

13. Vanderauwera, J., Hellemans, E. \& Verhaert, N. Research Insights on Neural Effects of Auditory Deprivation and Restoration in Unilateral Hearing Loss: A Systematic Review. J. Clin. Med. (2020). doi:10.3390/jcm9030812

14. van der Heijden, K., Rauschecker, J. P., de Gelder, B. \& Formisano, E. Cortical mechanisms of spatial hearing. Nature Reviews Neuroscience (2019). doi:10.1038/s41583-019-0206-5

15. Burton, H., Firszt, J. B., Holden, T., Agato, A. \& Uchanski, R. M. Activation lateralization in human core, belt, and parabelt auditory fields with unilateral deafness compared to normal hearing. Brain Res.1454, 33-47 (2012).

16. Hanss, J. et al. The effect of long-term unilateral deafness on the activation pattern in the auditory cortices of French-native speakers: Influence of deafness side. BMC Neurosci.10, 1-11 (2009).

17. Khosla, D. et al. Differential ear effects of profound unilateral deafness on the adult human central auditory system. JARO - J. Assoc. Res. Otolaryngol.4, 235-249 (2003). 
18. Qiao, Y. et al. Downward cross-modal plasticity in single-sided deafness. Neuroimage (2019). doi:10.1016/j.neuroimage.2019.05.031

19. Cañete, O. M., Purdy, S. C., Brown, C. R. S., Neeff, M. \& Thorne, P. R. Impact of unilateral hearing loss on behavioral and evoked potential measures of auditory function in adults. J. Am. Acad. Audiol. (2019). doi:10.3766/jaaa.17096

20. Hine, J., Thornton, R., Davis, A. \& Debener, S. Does long-term unilateral deafness change auditory evoked potential asymmetries? Clin. Neurophysiol. (2008). doi:10.1016/j.clinph.2007.11.010

21. Kral, A., Hubka, P., Heid, S. \& Tillein, J. Single-sided deafness leads to unilateral aural preference within an early sensitive period. Brain (2013). doi:10.1093/brain/aws305

22. Kim, J. J., Gross, J., Morest, D. K. \& Potashner, S. J. Quantitative study of degeneration and new growth of axons and synaptic endings in the chinchilla cochlear nucleus after acoustic overstimulation. J. Neurosci. Res. (2004). doi:10.1002/jnr.20211

23. Kamke, M. R., Brown, M. \& Irvine, D. R. F. Plasticity in the tonotopic organization of the medial geniculate body in adult cats following restricted unilateral cochlear lesions. J. Comp. Neurol. (2003). doi:10.1002/cne.10586

24. Eggermont, J. J. Acquired hearing loss and brain plasticity. Hearing Research (2017). doi:10.1016/j.heares.2016.05.008

25. Fan, W. et al. Altered contralateral auditory cortical morphology in unilateral sudden sensorineural hearing loss. Otol. Neurotol. (2015). doi:10.1097/MA0.0000000000000892

26. Cai, Y. et al. Inhibition of Brain Area and Functional Connectivity in Idiopathic Sudden Sensorineural Hearing Loss With Tinnitus, Based on Resting-State EEG. Front. Neurosci. (2019). doi:10.3389/fnins.2019.00851

27. Cañete, O. M., Purdy, S. C., Neeff, M., Brown, C. R. S. \& Thorne, P. R. Cortical auditory evoked potential (CAEP) and behavioural measures of auditory function in a child with a single-sided deafness. Cochlear Implants Int. (2017). doi:10.1080/14670100.2017.1373499

28. Polonenko, M. J., Papsin, B. C. \& Gordon, K. A. Cortical plasticity with bimodal hearing in children with asymmetric hearing loss. Hear. Res. (2019). doi:10.1016/j.heares.2018.02.003

29. Debener, S., Makeig, S., Delorme, A. \& Engel, A. K. What is novel in the novelty oddball paradigm? Functional significance of the novelty P3 event-related potential as revealed by independent component analysis. Brain Res. Cogn. Brain Res.22, 309-21 (2005).

30. Han \& Dimitrijevic, A. Acoustic change responses to amplitude modulation: A method to quantify cortical temporal processing and hemispheric asymmetry. Front. Neurosci.9, (2015).

31. Delorme, A. \& Makeig, S. EEGLAB: an open source toolbox for analysis of single-trial EEG dynamics including independent component analysis. J. Neurosci. Methods134, 9-21 (2004).

32. Han, J. H. \& Dimitrijevic, A. Acoustic Change Responses to Amplitude Modulation in Cochlear Implant Users: Relationships to Speech Perception. Front. Neurosci. (2020). doi:10.3389/fnins.2020.00124 
33. Dimitrijevic, A., Pratt, H. \& Starr, A. Auditory cortical activity in normal hearing subjects to consonant vowels presented in quiet and in noise. Clin. Neurophysiol.124, 1204-15 (2013).

34. Seghier, M. L. Laterality index in functional MRI: methodological issues. Magn. Reson. Imaging (2008). doi:10.1016/j.mri.2007.10.010

35. Maris, E. \& Oostenveld, R. Nonparametric statistical testing of EEG- and MEG-data. J. Neurosci. Methods164, 177-90 (2007).

36. Palomäki, K. J., Tiitinen, H., Mäkinen, V., May, P. J. C. \& Alku, P. Spatial processing in human auditory cortex: The effects of 3D, ITD, and ILD stimulation techniques. Cogn. Brain Res. (2005). doi:10.1016/j.cogbrainres.2005.02.013

37. Spierer, L., Bellmann-Thiran, A., Maeder, P., Murray, M. M. \& Clarke, S. Hemispheric competence for auditory spatial representation. Brain (2009). doi:10.1093/brain/awp127

38. Kaiser, J., Lutzenberger, W., Preissl, H., Ackermann, H. \& Birbaumer, N. Right-hemisphere dominance for the processing of sound-source lateralization. J. Neurosci. (2000). doi:10.1523/jneurosci.20-1706631.2000

39. Burke, K. A., Letsos, A. \& Butler, R. A. Asymmetric performances in binaural localization of sound in space. Neuropsychologia (1994). doi:10.1016/0028-3932(94)00074-3

40. Zatorre, R. J. \& Belin, P. Spectral and temporal processing in human auditory cortex. Cereb. Cortex11, 946-53 (2001).

41. Okamoto, H., Stracke, H., Draganova, R. \& Pantev, C. Hemispheric asymmetry of auditory evoked fields elicited by spectral versus temporal stimulus change. Cereb. Cortex19, 2290-7 (2009).

42. Lecaignard, Françoise Bertrand, O., Caclin, A. \& Mattout, J. Evidence for implicit and adaptive deployment of precision weighting during passive listening: a simultaneous EEG/MEG study. bioRxiv (2018). doi:https://doi.org/10.1101/501221

43. Tissieres, I., Crottaz-Herbette, S. \& Clarke, S. Implicit representation of the auditory space: contribution of the left and right hemispheres. Brain Struct. Funct. (2019). doi:10.1007/s00429-019-01853-5

44. Papesh, M. A., Billings, C. J. \& Baltzell, L. S. Background noise can enhance cortical auditory evoked potentials under certain conditions. Clin. Neurophysiol.126, 1319-30 (2015).

45. Alain, C., Quan, J., McDonald, K. \& Van Roon, P. Noise-induced increase in human auditory evoked neuromagnetic fields. Eur. J. Neurosci. (2009). doi:10.1111/j.1460-9568.2009.06792.x

46. Ponton, C. W. et al. Plasticity in the adult human central auditory system: evidence from late-onset profound unilateral deafness. Hear. Res.154, 32-44 (2001).

47. Scheffler, K., Bilecen, D., Schmid, N., Tschopp, K. \& Seelig, J. Auditory cortical responses in hearing subjects and unilateral deaf patients as detected by functional magnetic resonance imaging. Cereb. Cortex8, 156-163 (1998).

48. Picton, T. Hearing in time: Evoked potential studies of temporal processing. Ear Hear.34, 385-401 (2013). 
49. Sonnadara, R. R., Alain, C. \& Trainor, L. J. Effects of spatial separation and stimulus probability on the event-related potentials elicited by occasional changes in sound location. Brain Res. (2006). doi:10.1016/j.brainres.2005.11.088

50. Boehnke, S. E. \& Phillips, D. P. Azimuthal tuning of human perceptual channels for sound location. J. Acoust. Soc. Am. (1999). doi:10.1121/1.428037

51. Bilecen, D. et al. Cortical reorganization after acute unilateral hearing loss traced by fMRI. Neurology (2000). doi:10.1212/wnl.54.3.765

52. Han, J.-H. et al. Auditory cortical activity to different voice onset times in cochlear implant users. Clin. Neurophysiol.127, 1603-17 (2016).

53. Makhdoum, M. J., Groenen, P. A. P., Snik, A. F. M. \& Van Den Broek, P. Intra- and interindividual correlations between auditory evoked potentials and speech perception in cochlear implant users. Scand. Audiol. (1998). doi:10.1080/010503998419650

54. Sandmann, P. et al. Evaluation of evoked potentials to dyadic tones after cochlear implantation. Brain132, 1967-1979 (2009).

\section{Figures}

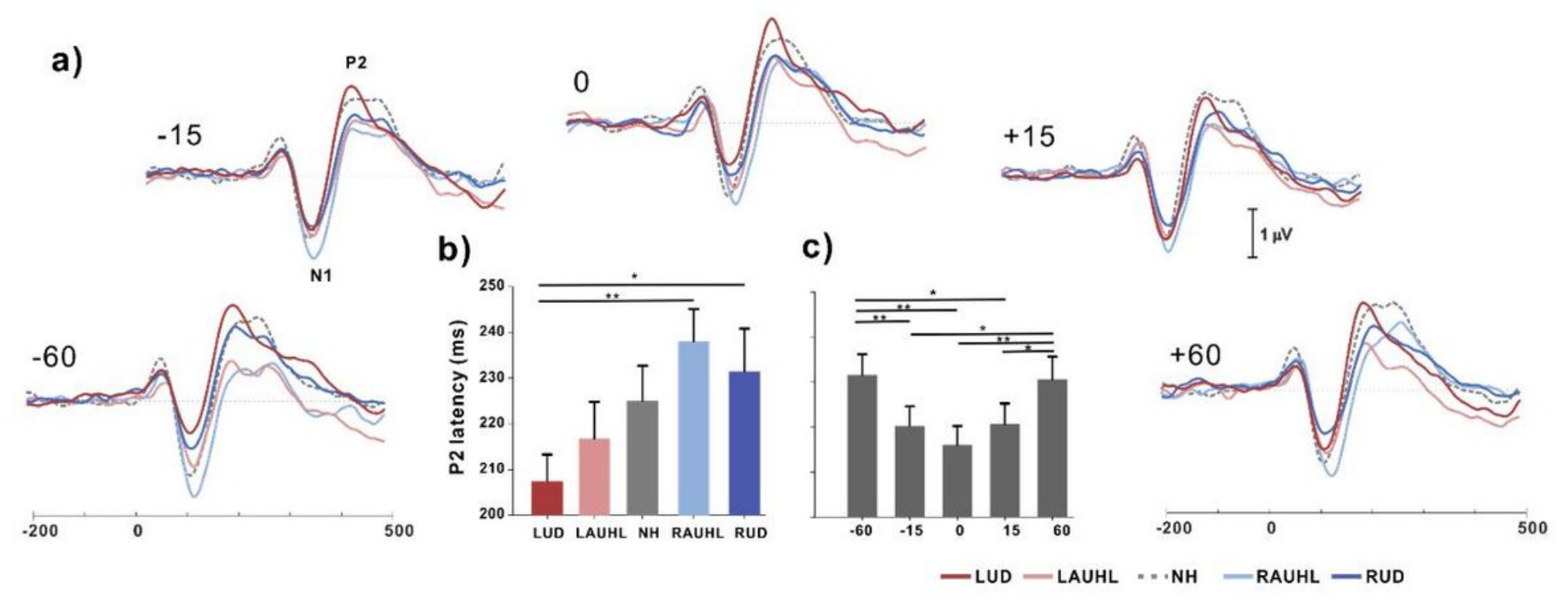

\section{Figure 1}

Grand mean waveforms to different sound locations. (a) Grand mean waveforms for the five different azimuth angles $\left(-60^{\circ},-15^{\circ}, 0^{\circ},+15^{\circ}\right.$, and $\left.+60^{\circ}\right)$ for the right and left unilaterally deaf (RUD and LUD, respectively), right and left acute unilateral hearing loss (RAUHL and LAUHL, respectively), and normal hearing $(\mathrm{NH})$ groups recorded with fronto-central $(\mathrm{FC})$ electrodes under passive listening conditions. In the middle of the figure, (b) P2 latencies (averaged across all azimuth angles) was significantly shorter for LUD than RAUHL and RUD groups. (c) P2 latencies (averaged across all groups) was significantly shorter 
for $-60^{\circ}$ and $+60^{\circ}$ compared to $-15^{\circ}, 0^{\circ}$, and $+15^{\circ}$ azimuth angles. Error bars: standard error of the mean. $\star P<0.05, * * P<0.01$.

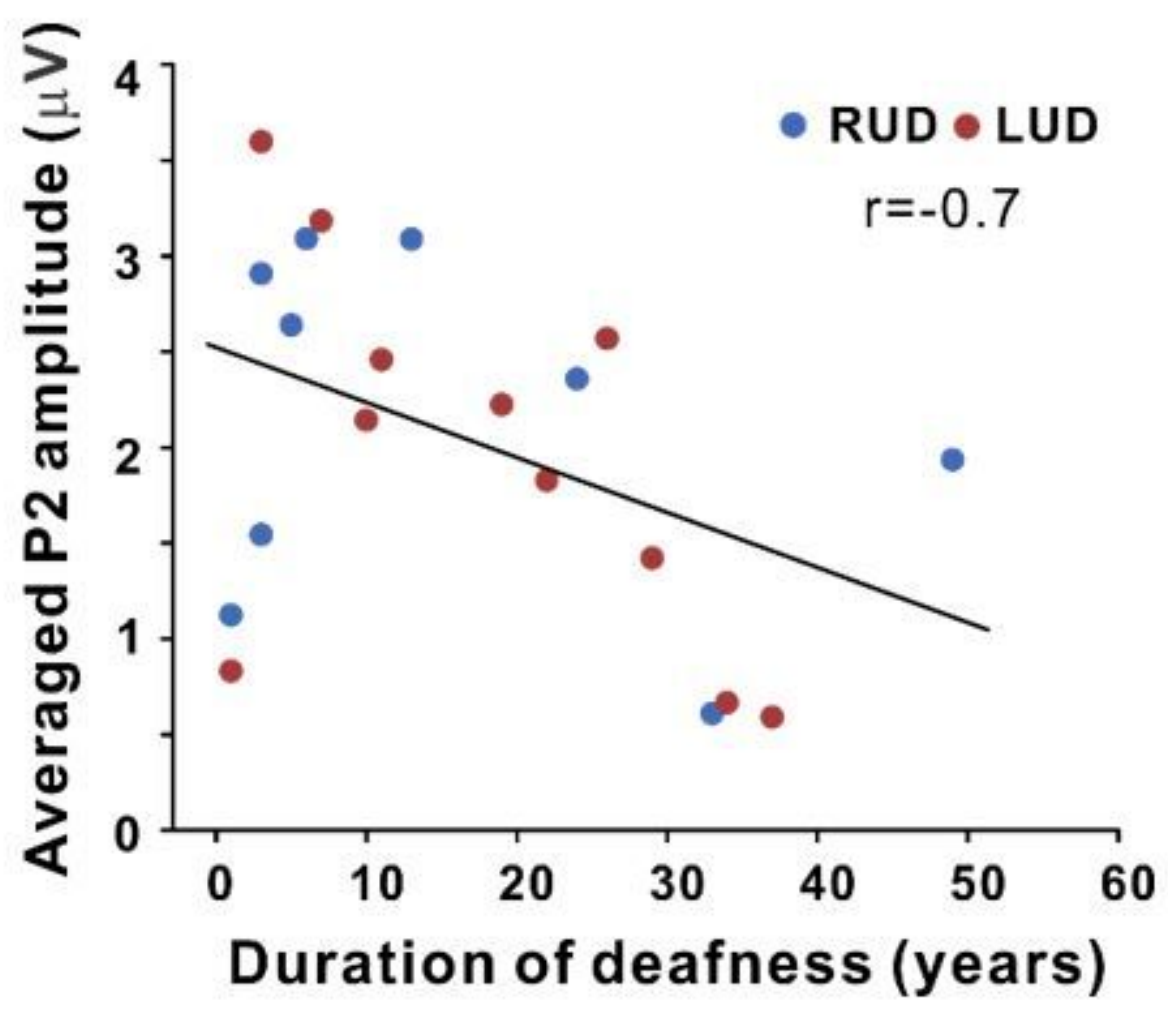

Figure 2

Significant inverse correlations between averaged P2 amplitudes and duration of deafness in unilateral deafness groups. 
a)

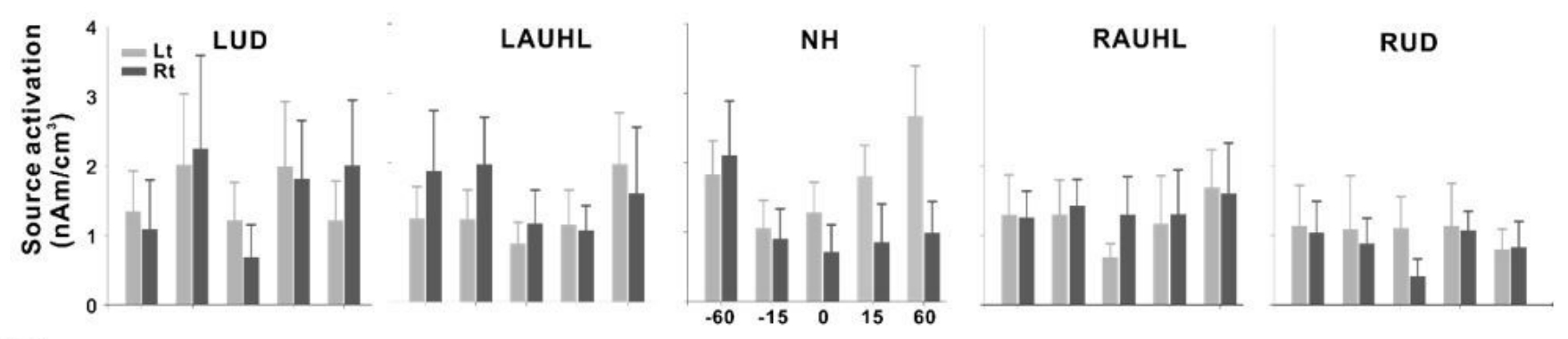

b)

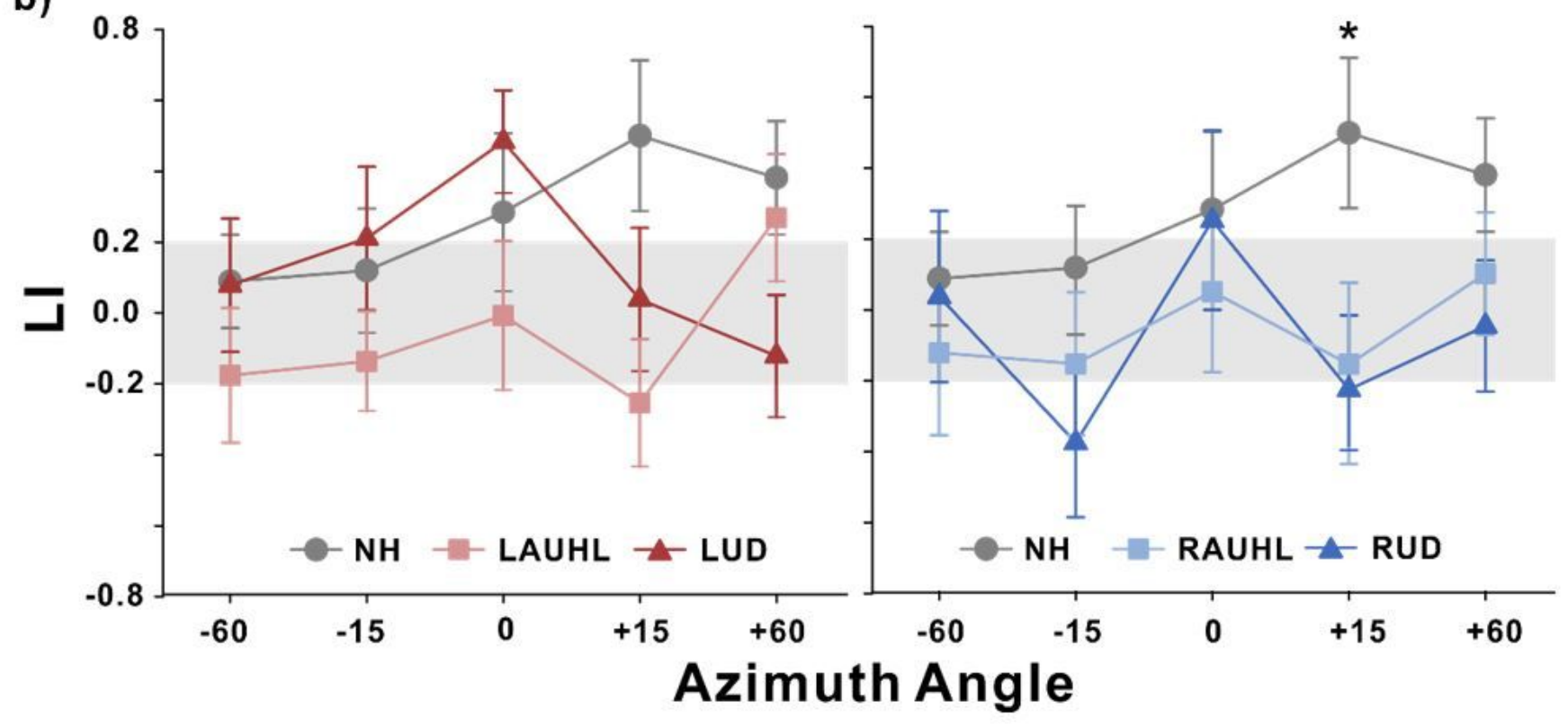

Figure 3

Mean swLORETA auditory source activation for different azimuth angles $\left(-60^{\circ},-15^{\circ}, 0^{\circ},+15^{\circ}\right.$, and $\left.+60^{\circ}\right)$ in the right and left unilaterally deaf (RUD and LUD, respectively), right and left acute unilateral hearing loss (RAUHL and LAUHL, respectively), and normal hearing ( $\mathrm{NH}$ ) groups. (a) The top rows indicating the mean responses in the left and right hemispheres are colored light gray and dark gray respectively. (b) The bottom rows indicate the lateralization index (LI) in the left column for the LUD, LAUHL, and NH groups, while the LIs for the RUD and RAUHL groups are shown in the right column. The results indicate that the LIs are significantly different at $+15^{\circ}$ such that the $\mathrm{NH}$ group subjects revealed larger $\mathrm{N} 1$ source activation in the left hemisphere, while the RUD and RAUHL groups were larger on the right. The gray regions in the LI plots indicate a 0.2 criterion for laterality. Error bars: standard error of the mean. ${ }^{*} \mathrm{P}<0.05$ 


\section{-60 vs +60}

\section{NH}
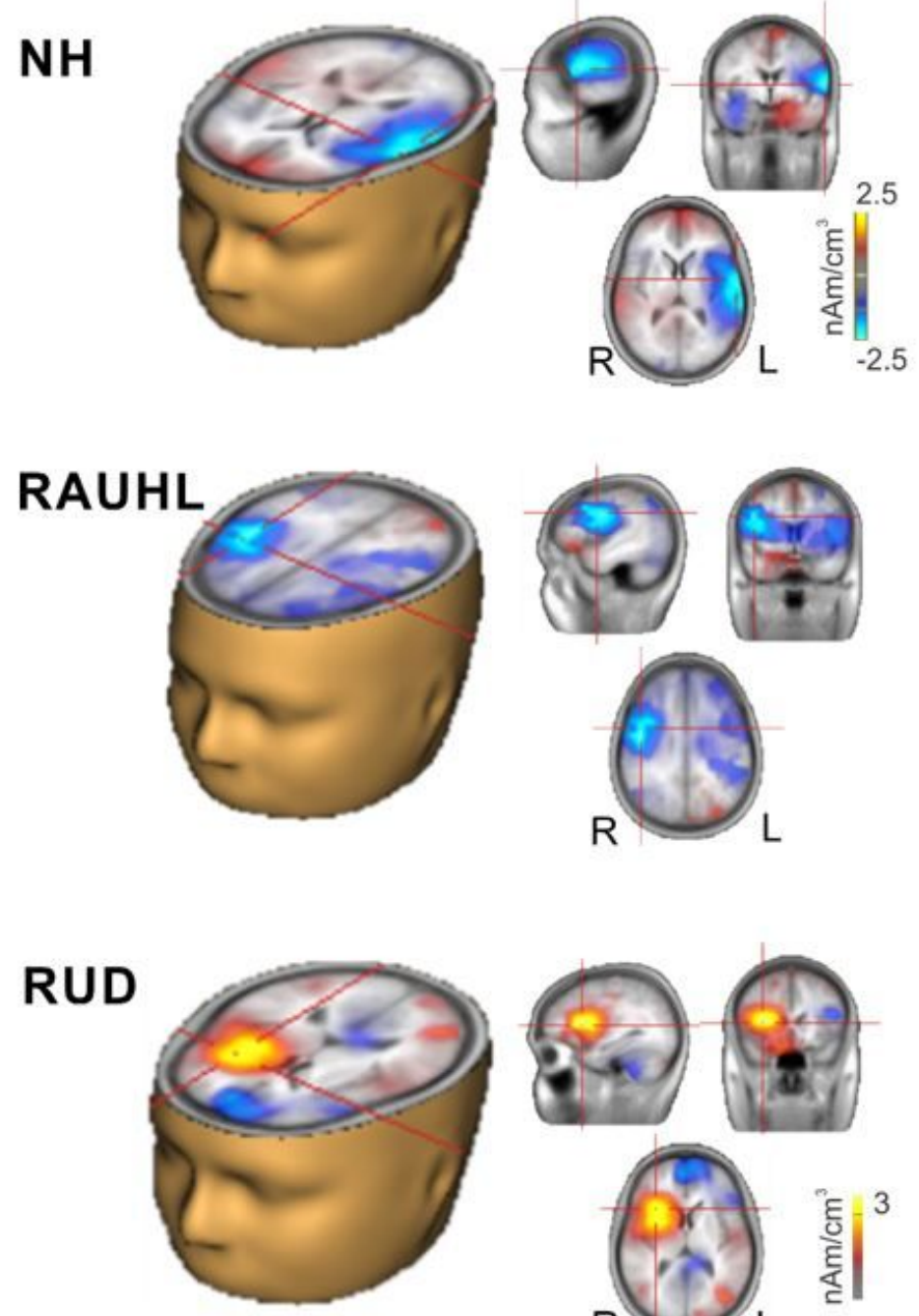

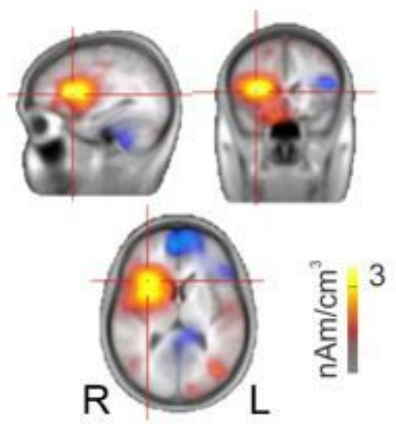

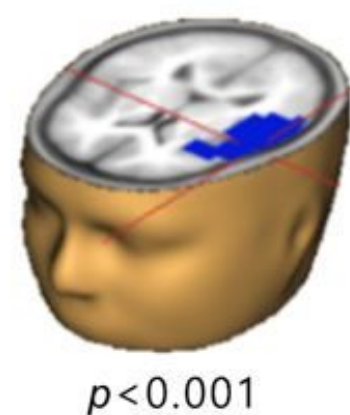

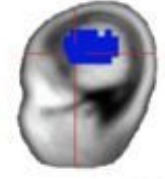

$-60>+60$

$-60<+60$

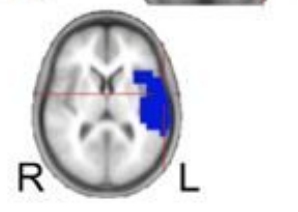

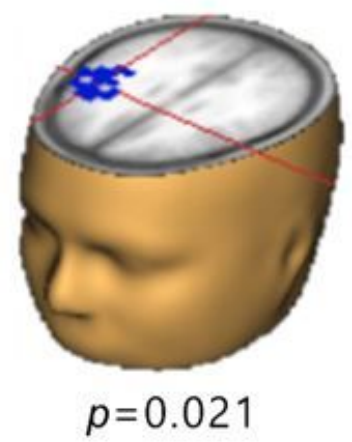
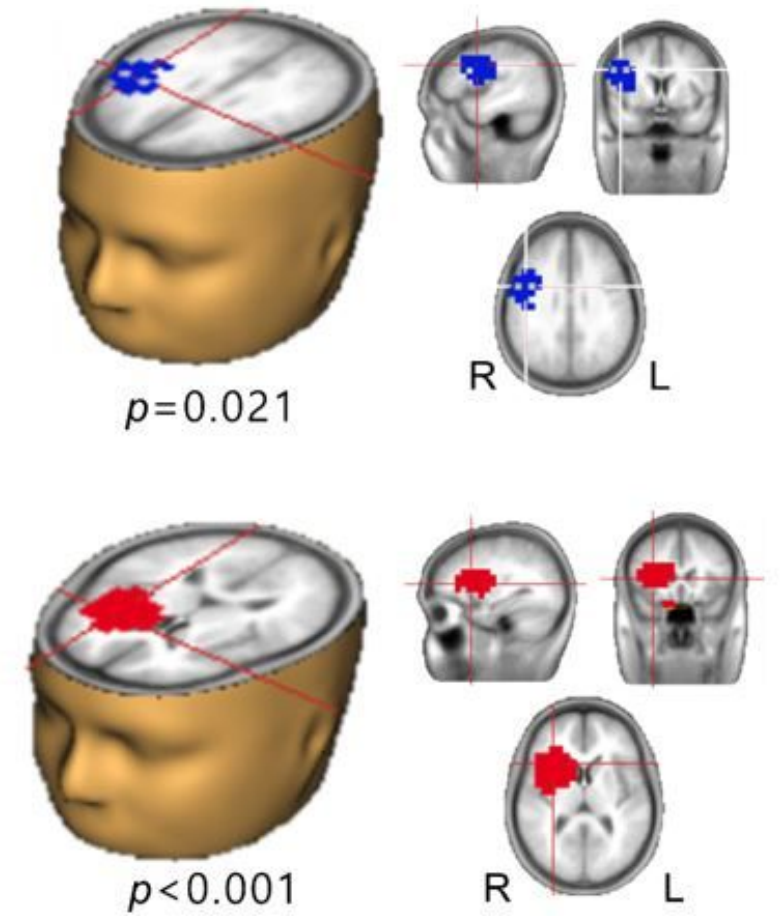

\section{Figure 4}

Cluster data representing significant differences between the $-60^{\circ}$ and $+60^{\circ}$ azimuth angles in the brain source space. Blue indicates that $+60^{\circ}$ was greater than $-60^{\circ}$ (a negative difference) while red indicates that $-60^{\circ}$ was greater than $+60^{\circ}$ (a positive difference). No significant differences were observed for the left-sided unilateral deafness (LUD) and hearing loss (LAUHL) groups. The normal hearing (NH) group subjects revealed larger activation on the left auditory region for $+60^{\circ}$ whereas the right-sided unilaterally deaf (RUD) and acute hearing loss (RAUHL) group subjects revealed greater activation in the right auditory and frontal regions for $+60^{\circ}$ and $-60^{\circ}$, respectively. Note that these clusters indicate which regions showed a significant difference while the cross-hairs indicate a 3D point indicating the maximum difference between the azimuth angles. 

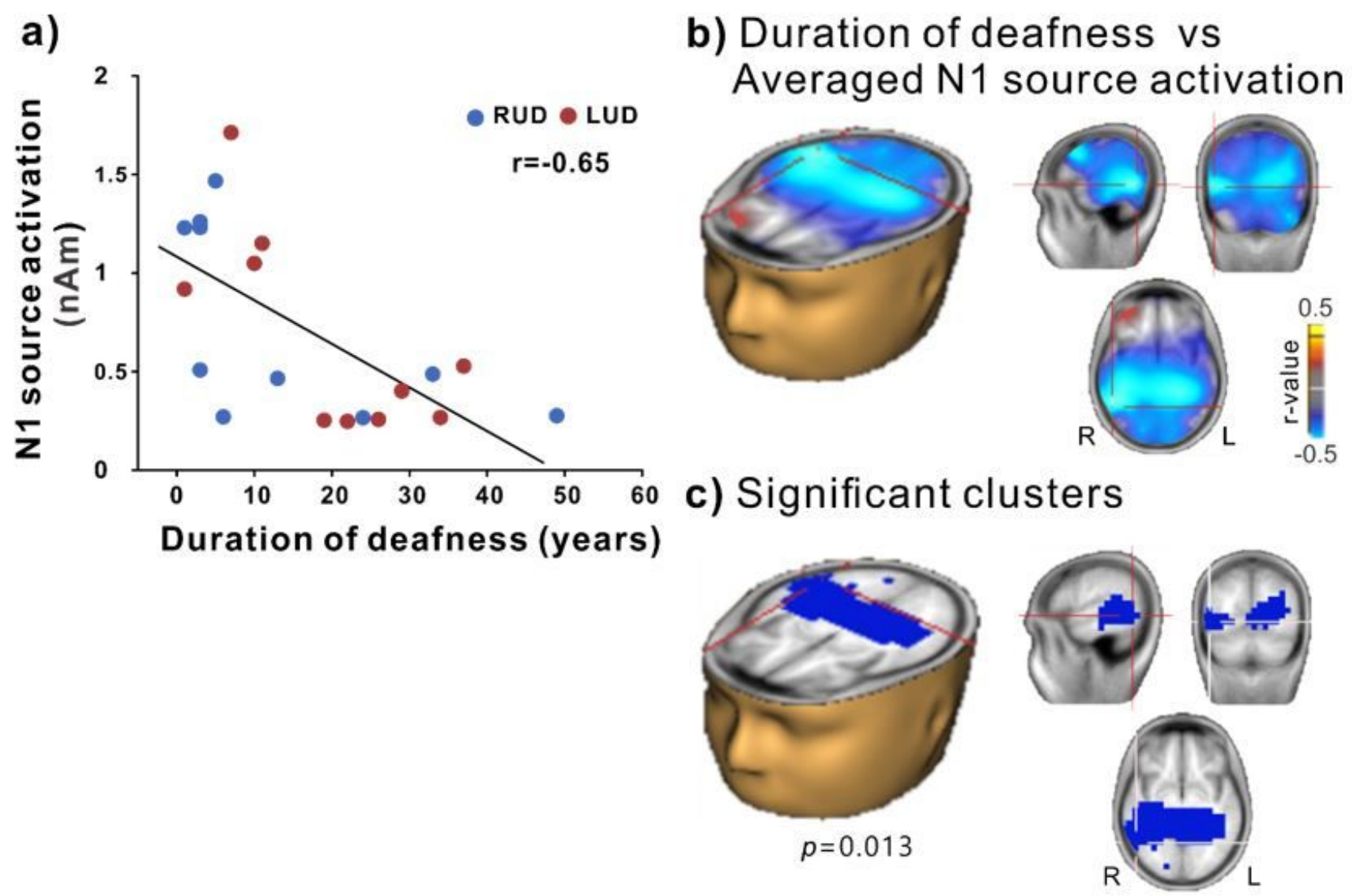

Figure 5

Correlation between $\mathrm{N} 1$ source activation and the duration of deafness. (a) N1 source activation is related to the duration of deafness in unilateral deafness groups. (b) Voxels representing correlations between the duration of deafness and the averaged $\mathrm{N} 1$ source activation across both unilateral deafness groups (significant clusters were found in the right temporal lobe). (c) Correlation data for voxels with peak correlations (cross-hairs). 
a)

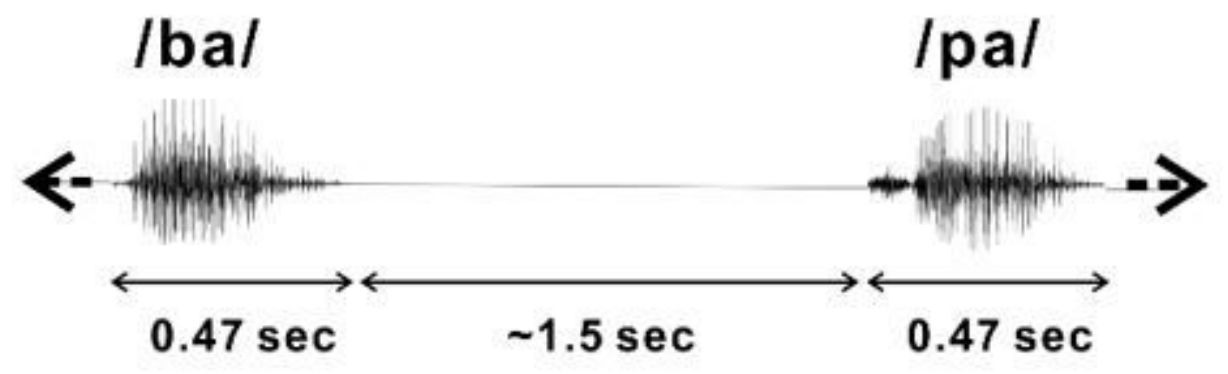

b)

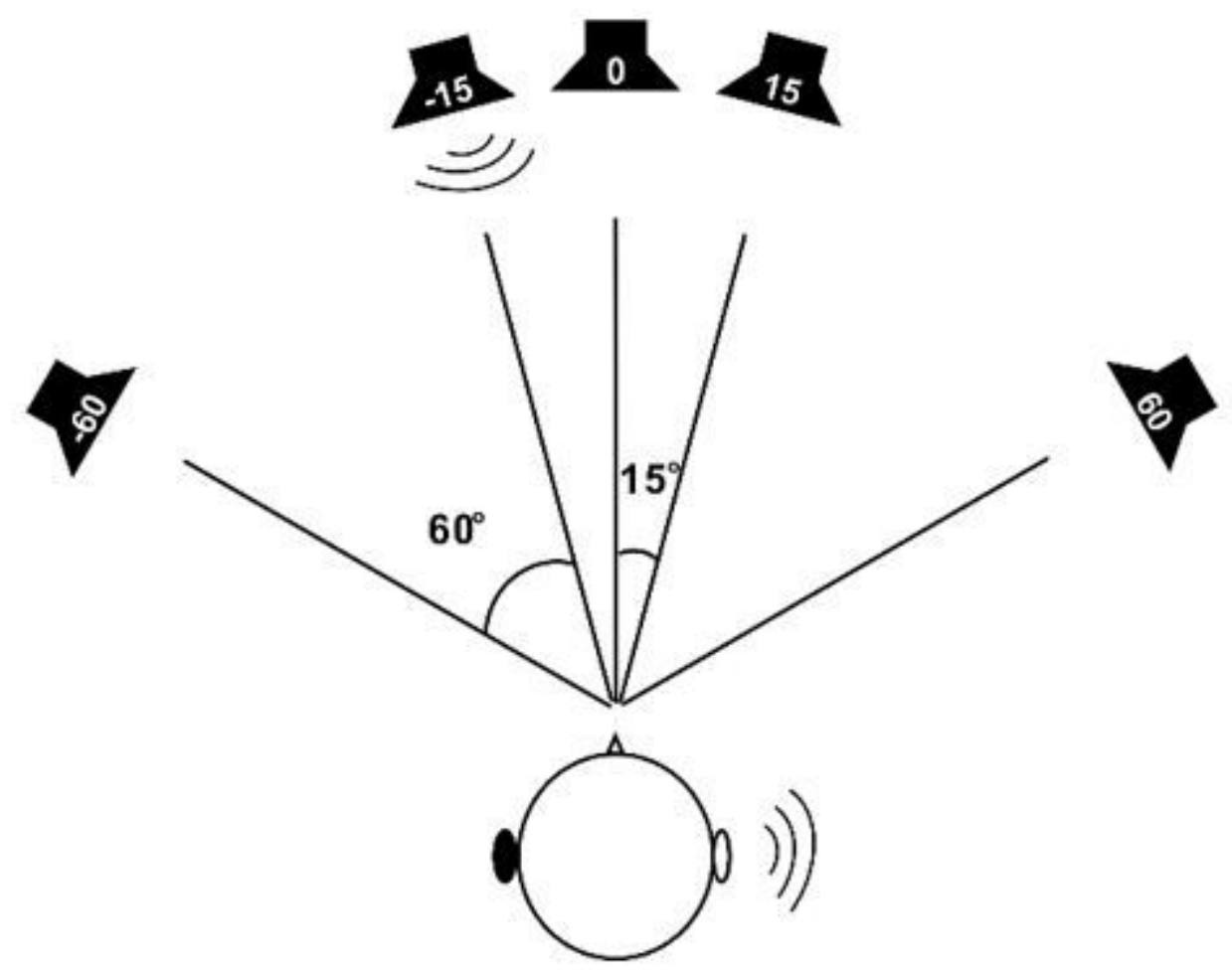

Figure 6

The acoustic stimuli used in the study. (a) An example of the acoustic sequence for the two sets of conditions: speech stimuli comprised of $/ \mathrm{ba} /$ and $/ \mathrm{pa} /$ were played for a duration of $0.47 \mathrm{~s}$ imbedded in $1.5 \mathrm{~s}$ inter-stimulus intervals. (b) Passive listening conditions during sound localization for five different azimuth angles $\left(-60^{\circ},-15^{\circ}, 0^{\circ},+15^{\circ}\right.$, and $\left.+60^{\circ}\right)$, where - indicates the left side while + indicates the right side. 